\title{
The Anterior Chamber Injection of Moxifloxacin Injection to Prevent Endophthalmitis after Cataract Surgery: A Meta-analysis
}

\author{
Xiao-lei Wang, ${ }^{1}$ Xiao-yong Huang, ${ }^{1}$ Zhen Wang, ${ }^{1}$ and Wei Sun $\mathbb{1 D}^{2}$ \\ ${ }^{1}$ Department of Ophthalmology, Southwest Hospital, Army Medical University, Chongqing 400038, China \\ ${ }^{2}$ Department of Emergency, Southwest Hospital, Army Medical University, Chongqing 400038, China \\ Correspondence should be addressed to Wei Sun; 1170661270@qq.com
}

Received 4 February 2020; Revised 17 May 2020; Accepted 19 June 2020; Published 25 August 2020

Academic Editor: Cosimo Mazzotta

Copyright ( 92020 Xiao-lei Wang et al. This is an open access article distributed under the Creative Commons Attribution License, which permits unrestricted use, distribution, and reproduction in any medium, provided the original work is properly cited.

Purpose. A meta-analysis was performed to compare the efficacy of an anterior chamber injection of moxifloxacin in the prevention of endophthalmitis after cataract surgery. Methods. A computer-based search of PubMed, Embase, the Cochrane Library, and the Clinical Trial database for articles related to anterior intraventricular injection of moxifloxacin for the prevention of endophthalmitis after cataract surgery was performed through April 2019. Study selection, data exclusion, and quality assessment were performed by two independent observers. Statistical analysis for the meta-analysis was performed by RevMan 5.3 software. Results. Eight studies were included, with a total of 123,819 eyes. The meta-analysis showed that an anterior chamber injection of moxifloxacin can prevent the incidence of endophthalmitis after cataract surgery $(\mathrm{OR}=0.29,95 \% \mathrm{CI}(0.15,0.56)$, $P=0.0002$ ), and the difference was statistically significant. There were no significant differences between the moxifloxacin injection and nonmoxifloxacin injection groups in regard to UCVA (log MAR) (SMD $=-0.13,95 \%$ CI $(-0.62,0.35), P=0.60)$, BCVA (log MAR) (SMD $=-0.27,95 \%$ CI $(-1.28,0.74), P=0.60)$, IOP (SMD $=-0.04,95 \%$ CI $(-0.02,0.01), P=0.22)$, corneal edema $(\mathrm{OR}=1.03,95 \% \mathrm{CI}(0.23,4.69), P=0.97)$, CCT $(\mathrm{SMD}=-0.01,95 \% \mathrm{CI}(-0.07,0.05), P=0.77)$, or $\mathrm{ECD}(\mathrm{SMD}=0.00,95 \%$ CI $(-0.06,0.07), P=0.94)$. Conclusion. An anterior chamber injection of moxifloxacin can effectively prevent the incidence of endophthalmitis after cataract surgery, while the moxifloxacin injection and nonmoxifloxacin injection groups had similar results in regard to UCVA (log MAR), BCVA (log MAR), IOP, corneal edema, CCT, and ECD.

\section{Background}

Endophthalmitis is one of the most serious complications after cataract surgery. Although rare, once it occurs, it is a complication that leads to poor visual prognosis [1]. According to the related literature [2], the incidence of endophthalmitis after cataract surgery is $0 \sim 0.63 \%$. There are several ways to prevent endophthalmitis, such as the use of povidone iodine, which can reduce the incidence of endophthalmitis [3]; antibiotic eye drops; subconjunctivals; anterior chamber injection; and antibacterial drug flushing [4-6]. In 2007, the European Association of Cataract and Refractive Surgeons (ESCRS) published a multicenter clinical trial that demonstrated the benefits of an anterior chamber injection of cefuroxime in preventing postoperative endophthalmitis [7]. In the recent years, the injection of antibacterial drugs in the anterior chamber has received increasing attention, and some related retrospective clinical studies and systematic reviews have been published. [8-10] However, with the increase in bacterial resistance, antibacterial drugs such as vancomycin and moxifloxacin have gradually begun to be used clinically to prevent postoperative endophthalmitis $[9,11]$. However, cefuroxime is less sensitive to drug-resistant bacteria, and the use of vancomycin may cause hemorrhagic occlusive retinal vasculitis. Therefore, it is more appropriate to prevent postoperative endophthalmitis via injection with moxifloxacin. However, due to the influence of the baseline characteristics, follow-up time, and research institutions of the included populations, the conclusions among studies have not been uniform. For this reason, we conducted this meta-analysis to provide a reference for the rational use of antibiotics in the perioperative period. 


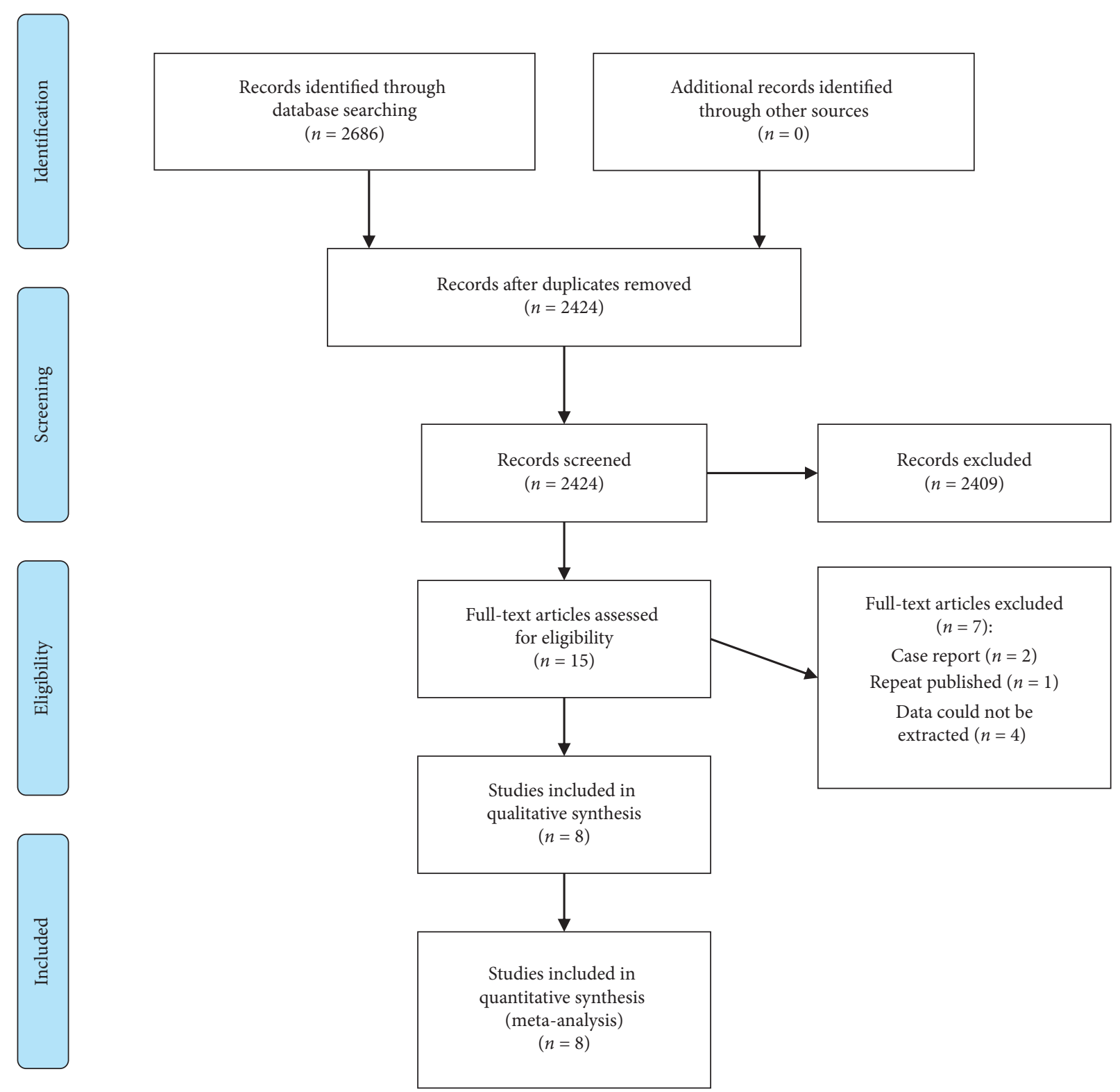

FIGURE 1: Flowchart of selection of studies for inclusion in the meta-analysis.

\section{Methods}

This review was conducted in accordance with the Preferred Reporting Items for Systematic Reviews and Meta-Analyses (PRISMA) guidelines and the recommendations of the Cochrane Collaboration.

2.1. Search Strategy. A computer search using PubMed, Embase, the Cochrane Library, and the Clinical Trial database for the intra-anterior injection of moxifloxacin to prevent endophthalmitis after cataract surgery was performed; the search time limit was from the establishment of the database to April 2019. The search terms were moxifloxacin, moxifloxacin hydrochloride, ophthalmologic surgical procedures, cataract extraction, vitrectomies, keratoplasties, intraocular lens implantations, glaucoma procedures, strabotomies, retinal detachment repair, laser in situ keratomileusis, and laser-assisted subepithelial keratectomy.

2.2. Eligibility Criteria. (1) Study designs: RCTs, case-control studies, or cohort studies. (2) Types of participants: eligible for cataract surgery; no limitation regarding age, sex, and race; and absence of moxifloxacin allergy, traumatic cataract with perforation of the eye, cataract surgery combined with other operations (such as glaucoma filtration surgery, vitreoretinal surgery, or corneal surgery), eye or periocular infection, advanced glaucoma, and severe ocular surface disease. (3) Intervention: anterior chamber injection of moxifloxacin, frequency of administration, dose, and concentration. (4) Outcomes: the incidence of endophthalmitis, uncorrected visual acuity (UCVA), best corrected visual 
TABle 1: Characteristics of the included studies $(n=8)$.

\begin{tabular}{|c|c|c|c|c|c|c|c|c|c|}
\hline \multirow[t]{2}{*}{ Study } & \multirow[t]{2}{*}{ Site } & \multirow[t]{2}{*}{ Designs } & \multicolumn{2}{|c|}{$\begin{array}{c}\text { The number of the } \\
\text { eyes }\end{array}$} & \multicolumn{2}{|c|}{ Age } & \multirow{2}{*}{$\begin{array}{l}\text { Treatment } \\
\text { options }\end{array}$} & \multirow{2}{*}{$\begin{array}{l}\text { Follow- } \\
\text { up }\end{array}$} & \multirow[t]{2}{*}{ Outcomes } \\
\hline & & & Moxifloxacin & Control & Moxifloxacin & Control & & & \\
\hline $\begin{array}{l}\text { Melega } \\
\text { et al. [11] }\end{array}$ & Brazil & RCT & 1818 & 1822 & $68.50 \pm 9.72$ & $68.49 \pm 9.63$ & $\begin{array}{c}0.5 \% \\
\text { moxifloxacin }\end{array}$ & $6 \mathrm{w}$ & $\begin{array}{l}\text { ECD, IOP, CCT, } \\
\text { and the incidence of } \\
\text { endophthalmitis }\end{array}$ \\
\hline $\begin{array}{l}\text { Lane et al. } \\
{[17]}\end{array}$ & USA & RCT & 26 & 31 & $74 \pm 9.3$ & $74 \pm 9.3$ & $\begin{array}{c}0.5 \% \\
\text { moxifloxacin }\end{array}$ & $3 \mathrm{~m}$ & $\begin{array}{l}\text { UCVA, IOP, ECD, } \\
\text { and CCT }\end{array}$ \\
\hline $\begin{array}{l}\text { Cetinkaya } \\
\text { et al. [12] }\end{array}$ & Turkey & $\begin{array}{l}\text { Case- } \\
\text { control } \\
\text { study }\end{array}$ & 33 & 32 & $64.81 \pm 11.61$ & $65.43 \pm 11.10$ & $\begin{array}{c}0.5 \% \\
\text { moxifloxacin }\end{array}$ & $1 \mathrm{y}$ & $\begin{array}{l}\text { BCVA, IOP, and } \\
\text { corneal edema }\end{array}$ \\
\hline $\begin{array}{l}\text { Rudnisky } \\
\text { et al. [13] }\end{array}$ & Canada & $\begin{array}{l}\text { Case- } \\
\text { control } \\
\text { study }\end{array}$ & 33039 & 42256 & NA & NA & $\begin{array}{c}0.5 \% \\
\text { moxifloxacin }\end{array}$ & $6 \mathrm{w}$ & $\begin{array}{l}\text { The incidence of } \\
\text { endophthalmitis }\end{array}$ \\
\hline $\begin{array}{l}\text { Virgilio } \\
\text { et al. [18] }\end{array}$ & Colombia & $\begin{array}{l}\text { Cohort } \\
\text { study }\end{array}$ & 1618 & 1056 & $67.2 \pm 11.3$ & $67.2 \pm 11.3$ & $\begin{array}{c}0.5 \% \\
\text { moxifloxacin }\end{array}$ & $2 \mathrm{w}$ & $\begin{array}{l}\text { The incidence of } \\
\text { endophthalmitis }\end{array}$ \\
\hline $\begin{array}{l}\text { Matsuura } \\
\text { et al. [15] }\end{array}$ & Japan & $\begin{array}{l}\text { Cohort } \\
\text { study }\end{array}$ & 69 & 69 & $71.9 \pm 7.5$ & $71.9 \pm 7.5$ & $\begin{array}{c}0.5 \% \\
\text { moxifloxacin }\end{array}$ & $3 \mathrm{~m}$ & $\begin{array}{l}\text { UCVA, BCVA, IOP, } \\
\text { ECD, and CCT }\end{array}$ \\
\hline $\begin{array}{l}\text { Matsuura } \\
\text { et al., [16] }\end{array}$ & Japan & $\begin{array}{l}\text { Cohort } \\
\text { study }\end{array}$ & 18797 & 15958 & NA & NA & $\begin{array}{c}0.1 \%, 0.3 \% \text {, and } \\
0.5 \% \\
\text { moxifloxacin }\end{array}$ & $1 \mathrm{~m}$ & $\begin{array}{l}\text { The incidence of } \\
\text { endophthalmitis }\end{array}$ \\
\hline $\begin{array}{l}\text { Vieira et al. } \\
{[14]}\end{array}$ & Brazil & $\begin{array}{l}\text { Cohort } \\
\text { study }\end{array}$ & 3680 & 3515 & $67.7 \pm 9.03$ & $68.1 \pm 8.92$ & $\begin{array}{c}0.5 \% \\
\text { moxifloxacin } \\
\end{array}$ & $1 \mathrm{~m}$ & $\begin{array}{l}\text { The incidence of } \\
\text { endophthalmitis }\end{array}$ \\
\hline
\end{tabular}

Abbreviations: BCVA, best corrected visual acuity; UCVA, uncorrected visual acuity; IOP, intraocular pressure; ECD, corneal endothelial cell density; CCT, central corneal thickness; NA, data not available; y, year; m, month; w, week.

acuity (BCVA), intraocular pressure (IOP), corneal edema, corneal center thickness (CCT), and corneal endothelial cell density (ECD).

\subsection{Exclusion Criteria. The exclusion criteria were as fol-} lows: (1) animal experiments; (2) repeated publications; (3) the literature for which data could not be extracted; and (4) abstracts, reviews, or conference literature.

2.4. Data Extraction. Two researchers used a three-step method to independently screen the literature, in case of disagreement. First, the topic and abstract were read, the irrelevant literature was excluded, and then, the full text of the remaining articles was read to determine whether they were ultimately included. If there were differences, they were discussed with a third party. The data extraction included the following: the first author and study time, age, sex, follow-up time, treatment plan, timing of administration, number of eyes included in the study, research type, and outcome indicators.

Regarding quality assessment of RCTs, the Cochrane risk of bias tool was used to perform a methodological quality assessment of RCTs. Assessment items include randomization, blinding, allocation concealment, data integrity, selective reporting bias, and other sources of bias. Each item was evaluated as "high," "low," or "unclear." For non-RCTs, the literature quality was evaluated for case-control studies and cohort studies using the Newcastle-Ottawa Scale (NOS) for literature quality assessment.

2.5. Data Synthesis and Statistical Analysis. Statistical analysis was performed using RevMan5.3 software. The continuous variables used the standardized mean difference (SMD) and its 95\% confidence interval (CI) as the statistical analysis value; the odds ratio (OR) and its 95\% CI were selected for the two categorical variables. The heterogeneity between studies was investigated by the $Q$ test and $I^{2}$ test. If $P$ was $\leq 0.1$ or $I^{2}$ was $\geq 50 \%$, heterogeneity was considered significant. Sensitivity analysis was performed to determine whether the heterogeneity decreased after each study was excluded. If the heterogeneity was not reduced, a subgroup analysis was performed based on the clinical characteristics of these studies. In the sensitivity analysis and subgroup analysis, if the heterogeneity was not reduced, the random effects model was used and analyzed by the Mantel-Haenszel method. If there was no heterogeneity between studies, indicated by $P>0.1$ or $I^{2}<50 \%$, the analysis was performed using a fixed effect model. All the combined results were statistically significant according to $P<0.5$. A publication bias test was performed using a funnel plot.

\section{Result}

3.1. Search Results. A total of 2,686 articles were collected through relevant database searches and other resources, and 262 duplicates were deleted. After exclusion according to the topic, abstract, and intensive reading of the full text, 8 articles were finally included [11-18]. The literature was analyzed by Meta. The literature flow chart is shown in Figure 1.

3.2. Characteristics of Included Studies. This meta-analysis included 8 studies [11-18], with 123,819 eyes; 2 studies were RCTs [11, 17], 2 studies were case-control studies [12, 13], and 4 studies were cohort studies [14-16, 18]. Two studies 


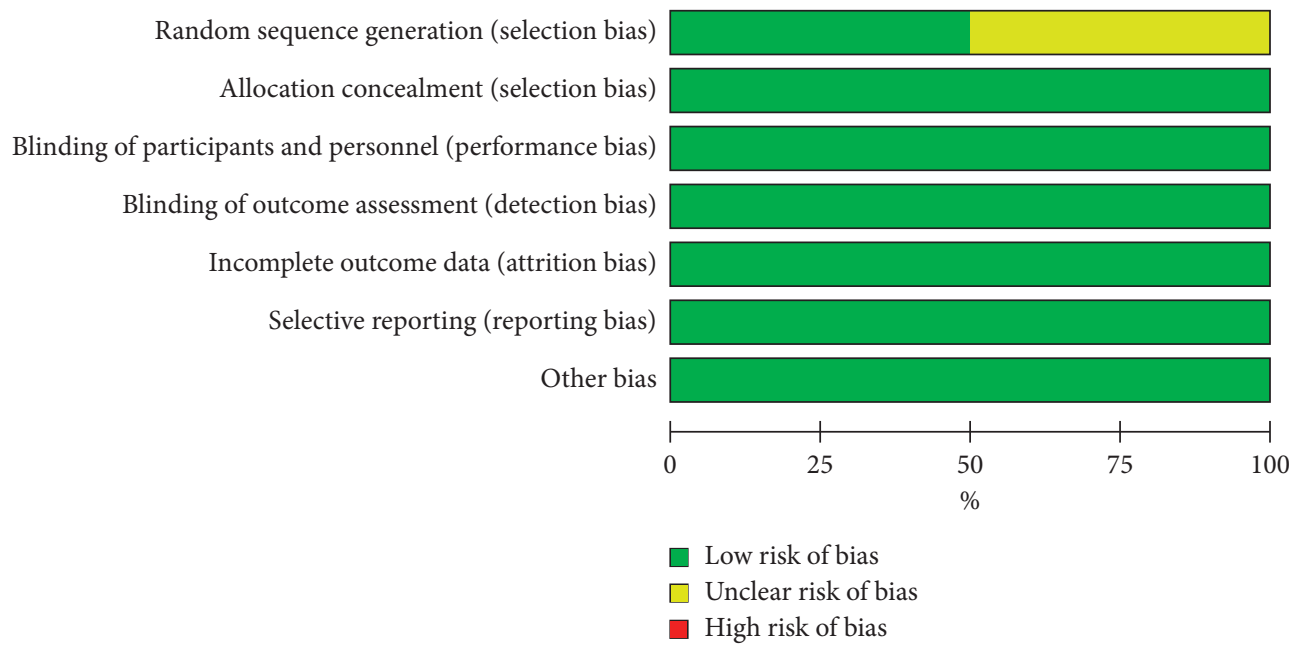

Figure 2: Risk of bias graph.

$[11,14]$ were conducted in Brazil, 1 study [17] was conducted in the USA, 1 study [12] was conducted in Turkey, 1 study [13] was conducted in Canada, 1 study [18] was conducted in Colombia, and 2 studies $[15,16]$ were conducted in Japan. The follow-up time ranged from 2 weeks to 1 year. The basic characteristics of the literature are shown in Table 1 .

3.2.1. Methodological Quality Evaluation. Two studies $[11,17]$ were RCTs, and we used the Cochrane risk of bias tool to assess these studies; the RCT quality evaluation results are shown in Figures 2 and 3. For non-RCTs [12-16, 18], we used the Newcastle-Ottawa scoring system to evaluate the quality of the literature. The total scores were 1 to 3,4 to 6 , and 7 to 9, representing low-, medium-, and high-quality studies, respectively. Two articles $[14,18]$ were of high quality, and $4[12,13,15,16]$ articles were of medium quality. The results of the non-RCT literature quality evaluation are shown in Table 2.

3.3. The Incidence of Endophthalmitis. We included 5 articles in this analysis $[11,13-15,18]$. There was no heterogeneity between the studies $\left(I^{2}=0 \%, P=0.73\right)$, and a fixed effect model was used. Meta-analysis showed that anterior chamber injection of moxifloxacin could prevent the incidence of endophthalmitis after cataract surgery $(\mathrm{OR}=0.29$, 95\% CI $(0.15,0.56), P=0.0002)$, and the difference was statistically significant, as shown in Figure 4.

3.4. UCVA. Two articles $[15,17]$ were included that reported UCVA (log MAR). The meta-analysis showed no significant difference between the moxifloxacin injection and nonmoxafloxacin injection $(\mathrm{SMD}=-0.13,95 \% \mathrm{CI}(-0.62,0.35)$, $P=0.60)$. Since $I^{2}=60 \%$, the random effects model was used for analysis, as shown in Figure 5.

3.5. BCVA. Two studies $[12,15]$ reported BCVA (log MAR). The meta-analysis showed no significant difference between

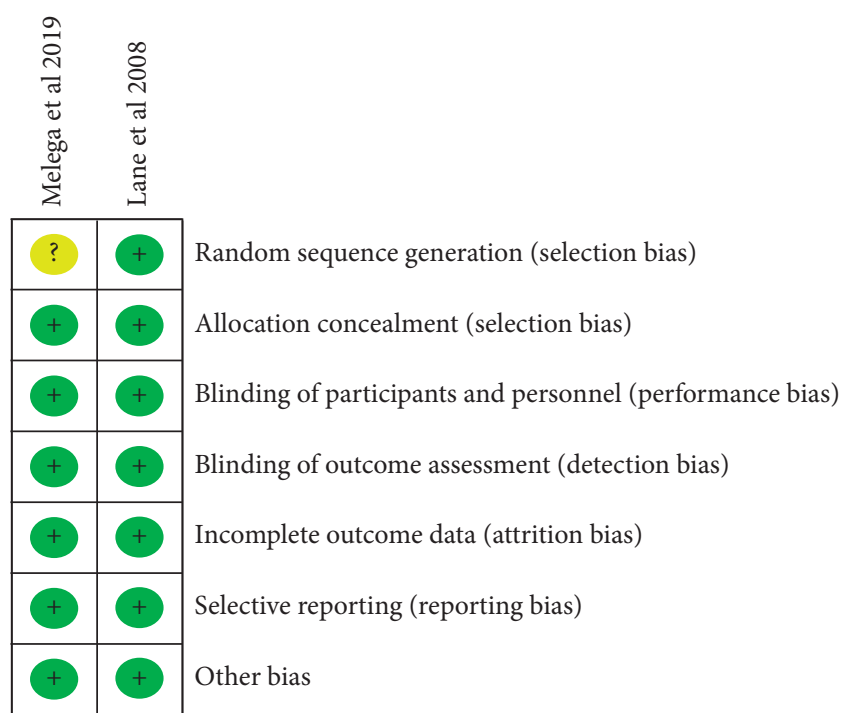

FiguRe 3: Risk of bias summary.

the moxifloxacin injection and nonmoxafloxacin injection $(\mathrm{SMD}=-0.27,95 \%$ CI $(-1.28,0.74), P=0.60)$. Since $I^{2}=91 \%$, the random effects model was used for analysis, as shown in Figure 6.

3.6. IOP. Four studies $[11,12,15,17]$ reported IOP with no heterogeneity between studies $\left(I^{2}=0 \%, P=0.98\right)$ using a fixed effect model. The meta-analysis showed no significant difference between the moxifloxacin injection and nonmoxafloxacin injection $(\mathrm{SMD}=-0.04,95 \% \mathrm{CI}(-0.02,0.01)$, $P=0.22)$; see Figure 7 .

3.7. Corneal Edema. Two studies [12, 17] reported corneal edema, with no heterogeneity between studies $\left(I^{2}=0 \%\right.$, $P=0.35)$; therefore, a fixed-effects model was used. The meta-analysis showed no significant difference between the moxifloxacin injection and nonmoxafloxacin injection $(\mathrm{OR}=1.03,95 \%$ CI $(0.23,4.69), P=0.97$, Figure 8$)$. 
TABLE 2: Quality assessment of included observational studies based on the Newcastle-Ottawa scale.

\begin{tabular}{lcccc}
\hline Study & Crowd selectivity (4 points) & Comparability (2 points) & Exposure evaluation (3 points) & Total (9 points) \\
\hline Cetinkaya et al. [12] & 3 & 0 & 3 & 3 \\
Rudnisky [13] & 3 & 0 & 3 & 6 \\
Galvis et al. [18] & 3 & 1 & 3 & 7 \\
Matsuura et al. [15] & 3 & 0 & 3 & 6 \\
Matsuura et al. [16] & 3 & 0 & 3 & 6 \\
Virgilio et al. [18] & 3 & 1 & & 7 \\
\hline
\end{tabular}

\begin{tabular}{|c|c|c|c|c|c|c|c|c|c|}
\hline \multirow{2}{*}{ Study or subgroup } & \multicolumn{2}{|c|}{ Moxifloxacin } & \multicolumn{2}{|c|}{ Control } & \multirow{2}{*}{$\begin{array}{l}\text { Weight } \\
(\%)\end{array}$} & \multirow{2}{*}{$\begin{array}{c}\text { Odds ratio } \\
\mathrm{M}-\mathrm{H} \text {, fixed, } 95 \% \mathrm{CI}\end{array}$} & \multirow{2}{*}{\multicolumn{2}{|c|}{$\begin{array}{c}\text { Odds ratio } \\
\mathrm{M}-\mathrm{H} \text {, fixed, } 95 \% \mathrm{CI}\end{array}$}} & \\
\hline & Events & Total & Events & Total & & & & & \\
\hline Matsuura et al. 2013 & 3 & 18797 & 8 & 15958 & 21.3 & $0.32[0.08,1.20]$ & $\longrightarrow$ & & \\
\hline Melega et al. 2019 & 1 & 1818 & 7 & 1822 & 17.2 & $0.14[0.02,1.16]$ & & & \\
\hline Rudnisky 2014 & 6 & 33039 & 17 & 42256 & 36.8 & $0.45[0.18,1.14]$ & 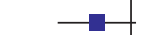 & & \\
\hline Vieira et al. 2017 & 1 & 3680 & 8 & 3515 & 20.2 & $0.12[0.01,0.95]$ & . & & \\
\hline Virgilio et al. 2014 & 0 & 1618 & 1 & 1056 & 4.5 & $0.22[0.01,5.34]$ & & & \\
\hline Total (95\% CI) & & 58952 & & 64607 & 100.0 & $0.29[0.15,0.56]$ & & & \\
\hline \multirow{2}{*}{\multicolumn{5}{|c|}{$\begin{array}{l}\text { Total events } \\
\text { Heterogeneity: chi }{ }^{2}=2.05, d f=4(P=0.73) ; I^{2}=0 \% \\
\text { Test for overall effect: } Z=3.70(P=0.0002)\end{array}$}} & & & & & \\
\hline & & & & & & 0.001 & 0.1 & 10 & 1000 \\
\hline & & & & & & & xifloxacin] & Favours & \\
\hline
\end{tabular}

FIGURE 4: Forest plot of the incidence of endophthalmitis.

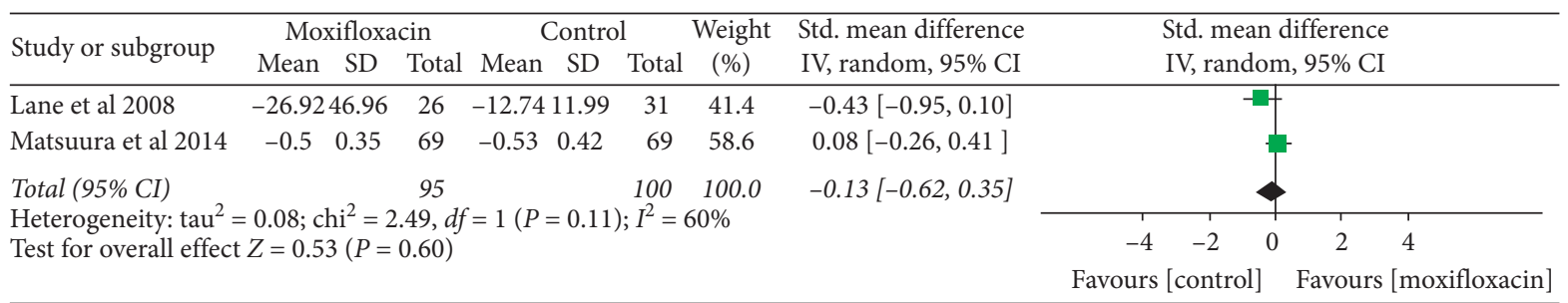

Figure 5: Forest plot of UCVA.

3.8. CCT. Three studies $[11,15,17]$ reported CCT, and there was no heterogeneity between the studies $\left(I^{2}=0 \%\right.$, $P=0.58)$; therefore, a fixed effect model was used. The metaanalysis showed no significant difference between the moxifloxacin injection and nonmoxifloxacin injection $(\mathrm{SMD}=-0.01,95 \% \mathrm{CI}(-0.07,0.05), P=0.77$, Figure 9$)$.

3.9. ECD. Three studies $[11,15,17]$ reported ECD, and there was no heterogeneity between the studies $\left(I^{2}=0 \%\right.$, $P=0.86)$; therefore, a fixed effect model was used. The metaanalysis showed no significant difference between the moxifloxacin injection and nonmoxifloxacin injection $(\mathrm{SMD}=0.00,95 \% \mathrm{CI}(-0.06,0.07), P=0.94$, Figure 10$)$.

\section{Discussion}

The incidence of endophthalmitis after cataract surgery is $0.012 \sim 0.053 \%$ in developed countries. [19] The incidence in large ophthalmology institutions in China is approximately $0.033 \%$ [20], and the incidence in small ophthalmology institutions has increased to $0.11 \%$ [21]. Because the incidence of endophthalmitis is extremely low, it is difficult to verify which preventive measures are the most effective through large RCTs, so most of the current research is observational in nature. Once endophthalmitis occurs, it can be life threatening. Perioperative use of antibiotic eye drops and preoperative conjunctival vesicle povidone iodine disinfection have been indicated to be the most effective measures to prevent endophthalmitis after cataract surgery. These measures have been considered the medical standards, and the anterior chamber injection of antibiotics' safety and efficacy have also been popular research topics. However, the most reasonable use of antibiotics as a preventive measure during the perioperative period is still controversial. Different methods of administration, timing, and the course of treatment of anti-inflammatory drugs for postoperative endophthalmitis have been proposed by ophthalmologists, but there is no consensus. After the European ESCRS study, the anterior chamber injection of cefuroxime has been widely recognized, and with increasing clinical bacterial resistance, some medical institutions have begun to use effective broad-spectrum antibiotics, such as moxifloxacin and vancomycin. The anterior chamber injection of strong antibiotics has been used to prevent endophthalmitis after cataract surgery. In clinical applications, the preparation of cefuroxime in the pharmacy will increase the risk of infection and toxic anterior segment syndrome. The temporary preparation in the operating room is prone to dose error, while the direct 


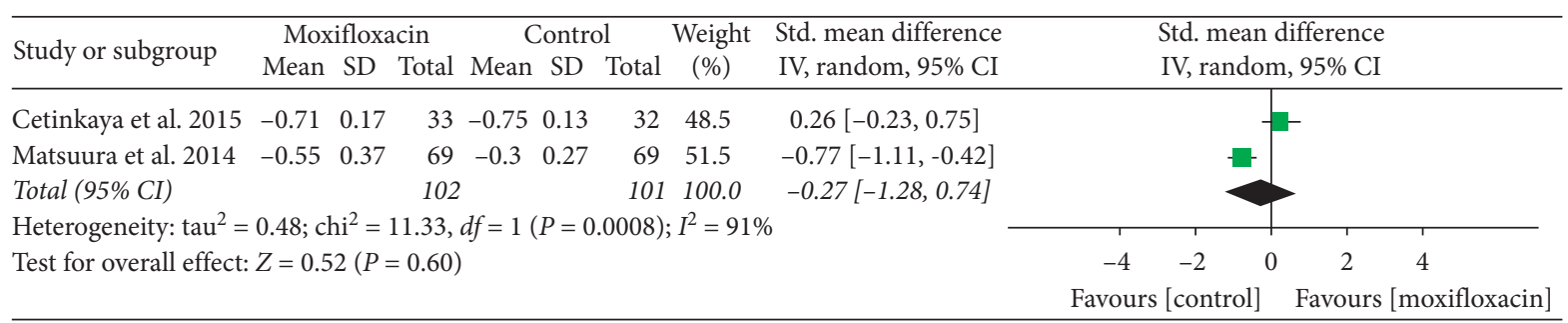

FIgURE 6: Forest plot of BCVA.

\begin{tabular}{|c|c|c|c|c|c|c|c|c|c|c|c|}
\hline \multirow{2}{*}{ Study or subgroup } & \multicolumn{3}{|c|}{ Moxifloxacin } & \multicolumn{3}{|c|}{ Control } & \multirow{2}{*}{$\begin{array}{l}\text { Weight } \\
(\%)\end{array}$} & \multirow{2}{*}{$\begin{array}{l}\text { Std. mean difference } \\
\text { IV, fixed, 95\% CI }\end{array}$} & \multirow{2}{*}{\multicolumn{3}{|c|}{$\begin{array}{l}\text { Std. mean difference } \\
\text { IV, fixed, } 95 \% \text { CI }\end{array}$}} \\
\hline & Mean & $\mathrm{SD}$ & Total & Mean & $\mathrm{SD}$ & Total & & & & & \\
\hline Cetinkaya et al. 2015 & -0.87 & 2.57 & 33 & -1.03 & 2.39 & 32 & 1.7 & $0.06[-0.42,0.55]$ & & & \\
\hline Lane et al. 2008 & -1.77 & 2.07 & 26 & -1.77 & 2.66 & 31 & 1.5 & $0.00[-0.52,0.52]$ & & & \\
\hline Matsuura et al. 2014 & -2.14 & 3.2 & 69 & -2.45 & 3.04 & 69 & 3.5 & $0.10[-0.24,0.43]$ & & & \\
\hline Melega et al. 2019 & -0.85 & 4.54 & 1818 & -1.02 & 4.6 & 1822 & 93.3 & $0.04[-0.03,0.10]$ & & & \\
\hline & & & 1946 & & & 1954 & 100.0 & $0.04[-0.02,0.10]$ & & & \\
\hline \multicolumn{7}{|c|}{$\begin{array}{l}\text { Heterogeneity: } \mathrm{chi}^{2}=0.16, d f=3(P=0.98) ; I^{2}=0 \% \\
\text { Test for overall effect: } Z=1.23(P=0.22)\end{array}$} & & & $\begin{array}{l}-0.5 \\
\text { Favours [moxifloxacin] }\end{array}$ & $\begin{array}{l}0.25 \\
\text { Favours [control] }\end{array}$ & 0.5 \\
\hline
\end{tabular}

Figure 7: Forest plot of IOP.

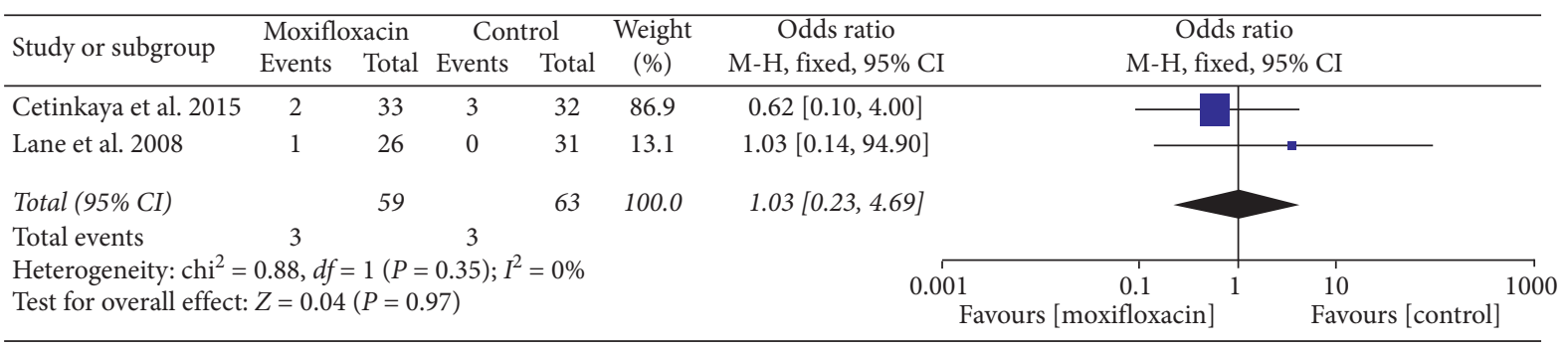

Figure 8: Forest plot of corneal edema.

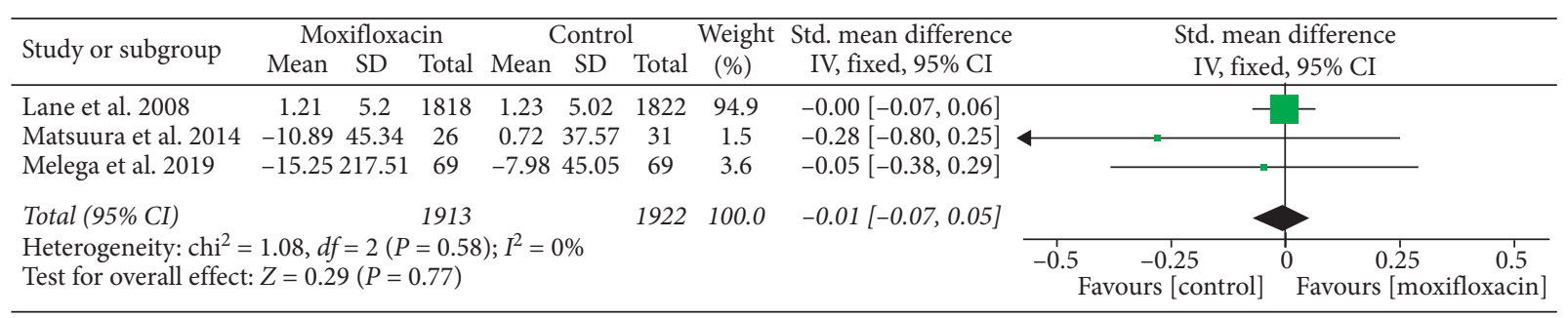

FIgURE 9: Forest plot of CCT.

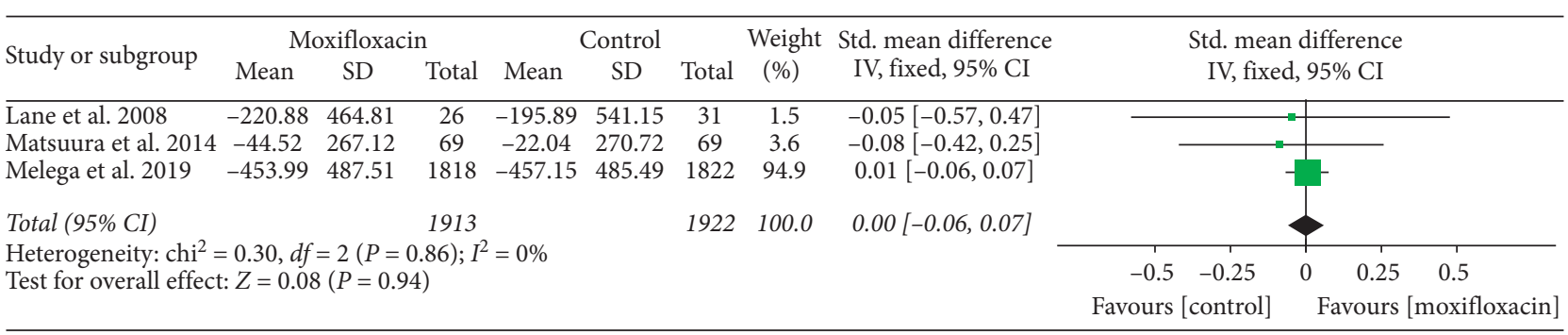

Figure 10: Forest plot of ECD.

injection of commercial cefuroxime is only available in Europe [22]. In addition, in a small number of cases, there is an allergic reaction associated with cefuroxime or transient macular edema caused by overdose $[23,24]$. The use of vancomycin may cause hemorrhagic occlusive retinal vasculitis. 
The results of this meta-analysis showed that the anterior chamber injection of moxifloxacin can prevent the incidence of endophthalmitis after cataract surgery $(\mathrm{OR}=0.29,95 \% \mathrm{CI}$ $(0.15,0.56), P=0.0002)$, and the difference was statistically significant. Regarding other indicators (UCVA (log MAR), BCVA (log MAR), IOP, corneal edema, CCT, and ECD), there was no significant difference between the moxifloxacin injection group and the nonmoxifloxacin injection group. Moxifloxacin has a wide range of antibacterial activities and is effective against Pseudomonas aeruginosa. Moxifloxacin is safe for patients allergic to penicillin and cephalosporin. It can be directly injected into the anterior chamber without preservative-containing eye drops. The operation is the simplest. Combined with the results of this study, it can be considered clinically safe to use the anterior chamber injection of moxifloxacin to prevent endophthalmitis after cataract surgery. However, due to the current small number of clinical studies and the lack of prospective RCTs, this study included only two RCTs; the rest were non-RCT studies, and there was a lack of direct comparison between moxifloxacin and cefuroxime. Therefore, large-sample, multicenter, high-quality RCTs are needed in the future to provide higher quality evidence.

The study was limited by the following factors: (1) Because the incidence of endophthalmitis after cataract surgery is extremely low, most studies are observational; however, there is much evidence that the anterior chamber injection of moxifloxacin can prevent endophthalmitis. The incidence of posterior endophthalmitis, which is not used by clinicians, was not possible to assess mainly due to a lack of highquality evidence from RCTs. (2) The follow-up time of some of the included studies was short, so we may have underestimated drug-induced adverse events. (3) Heterogeneity is unavoidable due to factors such as different drug administration schedules, different follow-up times, and differences in the population. (4) In addition to the significant difference in the incidence of endophthalmitis in this study, the difference in other indicators was not statistically significant, which may be due to the lack of included studies and the small sample size. Therefore, the advantages of the moxifloxacin injection in these areas have not been shown.

\section{Conclusions}

The results of this meta-analysis showed that compared with a nonmoxifloxacin injection, an anterior chamber injection of moxifloxacin was effective in preventing the incidence of endophthalmitis after cataract surgery, and the moxifloxacin injection exhibited in similar results as a nonmoxifloxacin injection in UCVA (log MAR), BCVA (log MAR), IOP, corneal edema, CCT, and ECD. Therefore, to obtain more meaningful results, a larger sample size RCT should be performed.

\section{Data Availability}

The data used to support this study were from NCBI PubMed. The data sets used and/or analyzed during the present study are available from the corresponding author on reasonable request.

\section{Conflicts of Interest}

The authors declare that they have no conflicts of interest.

\section{Acknowledgments}

This study was supported by the Southwest Military Hospital Science and Technology Innovation Fund of the Third Military Medical University (SWHLKJ-CO1).

\section{References}

[1] N. K. George and M. W. Stewart, "The routine use of intracameral antibiotics to prevent endophthalmitis after cataract surgery: how good is the evidence?" Ophthalmology and Therapy, vol. 7, no. 2, pp. 233-245, 2018.

[2] D. W. Bratzler, E. P. Dellinger, K. M. Olsen et al., "Clinical practice guidelines for antimicrobial prophylaxis in surgery," Surgical Infections, vol. 14, no. 1, pp. 73-156, 2013.

[3] A. Şahin and Y. Çınar, "Intracameral povidone-iodine for endophthalmitis treatment," International Ophthalmology, vol. 38, no. 6, pp. 2269-2270, 2018.

[4] R. E. Fintelmann and A. Naseri, "Prophylaxis of postoperative endophthalmitis following cataract surgery," Drugs, vol. 70, no. 11, pp. 1395-1409, 2010.

[5] V. Jayesh and B. Sayan, "Role of topical, subconjunctival, intracameral, and irrigative antibiotics in cataract surgery," Current Opinion in Ophthalmology, vol. 24, pp. 60-65, 2013.

[6] A. Grzybowski, P. Kuklo, J. Pieczynski, and G. Beiko, "A review of preoperative manoeuvres for prophylaxis of endophthalmitis in intraocular surgery," Current Opinion in Ophthalmology, vol. 27, no. 1, pp. 9-23, 2016.

[7] C. Grasso, "Prophylaxis of postoperative endophthalmitis following cataract surgery: results of the ESCRS multicenter study and identification of risk factors," Journal of Cataract \& Refractive Surgery, vol. 33, pp. 978-988, 2007.

[8] J. Huang, X. Wang, X. Chen et al., "Perioperative antibiotics to prevent acute endophthalmitis after ophthalmic surgery: a systematic review and meta-analysis," PLoS One, vol. 11, Article ID e0166141, 2016.

[9] R. C Bowen, A. X Zhou, S. Bondalapati et al., "Comparative analysis of the safety and efficacy of intracameral cefuroxime, moxifloxacin and vancomycin at the end of cataract surgery: a meta-analysis," The British Journal of Ophthalmology, vol. 102, pp. 1268-1276, 2018.

[10] L. Kessel, P. Flesner, J. Andresen et al., “Antibiotic prevention of postcataract endophthalmitis: a systematic review and meta-analysis," Acta Ophthalmologica, vol. 93, pp. 303-317, 2015.

[11] M. V. Melega, M. Alves, R. P. C. Lira et al., "Safety and efficacy of intracameral moxifloxacin for prevention of post-cataract endophthalmitis: randomized controlled clinical trial," Journal of Cataract \& Refractive Surgery, vol. 45, no. 3, pp. 343350, 2019.

[12] S. Cetinkaya, Y. F. Cetinkaya, N. O. Acir et al., "Application of intracameral moxifloxacin to prevent endophthalmitis in cataract surgery," International Eye Science, vol. 15, pp. 1680-1683, 2015.

[13] C. J. Rudnisky, D. Wan, and E. Weis, "Antibiotic choice for the prophylaxis of post-cataract extraction endophthalmitis," Ophthalmology, vol. 121, no. 4, pp. 835-841, 2014.

[14] I. V. Vieira, C. Boianovsky, T. J. Saraiva et al., "Safety and efficacy of intracameral moxifloxacin injection for 
prophylaxis of endophthalmitis after phacoemulsification," Arquivos brasileiros de oftalmologia, vol. 80, pp. 165-167, 2017.

[15] K. Matsuura, C. Suto, Y. Inoue, S.-i. Sasaki, S. Odawara, and T. Gotou, "Safety of intracameral injection of moxifloxacin using total replacement technique (bag and chamber flushing)," Journal of Ocular Pharmacology and Therapeutics, vol. 30, no. 9, pp. 771-776, 2014.

[16] K. Matsuura, T. Miyoshi, C. Suto, J. Akura, and Y. Inoue, "Efficacy and safety of prophylactic intracameral moxifloxacin injection in Japan," Journal of Cataract \& Refractive Surgery, vol. 39, no. 11, pp. 1702-1706, 2013.

[17] S. S. Lane, R. H. Osher, S. Masket, and S. Belani, "Evaluation of the safety of prophylactic intracameral moxifloxacin in cataract surgery," Journal of Cataract \& Refractive Surgery, vol. 34, no. 9, pp. 1451-1459, 2008.

[18] G. Virgilio, T. Alejandro, S. Mary Alejandra et al., "Cohort study of intracameral moxifloxacin in postoperative endophthalmitis prophylaxis," Ophthalmology and Eye Diseases, vol. 6, pp. 1-4, 2014.

[19] C. Chiquet, S. Boisset, A. Pechinot, C. Creuzot-Garcher, F. Aptel, and A. M. Bron, "Massilia timonae as cause of chronic endophthalmitis following cataract surgery," Journal of Cataract \& Refractive Surgery, vol. 41, no. 8, pp. 1778-1780, 2015.

[20] Y. Ke, Z. Yanan, Z. Zhihong et al., "The incidence of postoperative endophthalmitis after cataract surgery in China: a multicenter investigation of 2006-2011," British Journal of Ophthalmology, vol. 97, pp. 1312-1317, 2013.

[21] Y. Zhu, X. Chen, P. Chen et al., "The occurrence rate of acuteonset postoperative endophthalmitis after cataract surgery in Chinese small- and medium-scale departments of ophthalmology," Scientific Reports, vol. 7, p. 40776, 2017.

[22] A. Haripriya and D. F. Chang, "Intracameral antibiotics during cataract surgery: evidence and barriers," Current Opinion in Ophthalmology, vol. 29, p. 1, 2018.

[23] E. Moisseiev and E. Levinger, "Anaphylactic reaction following intracameral cefuroxime injection during cataract surgery," Journal of Cataract \& Refractive Surgery, vol. 39, no. 9, pp. 1432-1434, 2013.

[24] D. C. Wong, M. D. Waxman, L. J. Herrinton, and N. H. Shorstein, "Transient macular edema after intracameral injection of a moderately elevated dose of cefuroxime during phacoemulsification surgery," JAMA Ophthalmology, vol. 133, no. 10, pp. 1194-1197, 2015. 